\title{
Risk factors contributing to the incidence and mortality of acute childhood poisoning in emergency department patients in Iran: a hospital-based case- control study
}

\author{
Hamideh Feiz Disfani' ${ }^{1}$ Mostafa Kamandi², Seyed Mohammad Mousavi', \\ Sayyed Majid Sadrzadeh', Roohie Farzaneh', Najme Doolabi', Kazem Rahmani \\ 'Department of Emergency Medicine, Faculty of Medicine, Mashhad University of Medical Sciences, Mashhad, Iran; ${ }^{2}$ Department of Internal \\ Medicine, Faculty of Medicine, Mashhad University of Medical Sciences, Mashhad, Iran; ${ }^{3}$ Department of Epidemiology, School of Public Health, \\ Iran University of Medical Sciences, Tehran, Iran
}

OBJECTIVES: Since poisoning is one of the most important preventable factors contributing to the hospitalization and death of children who present to emergency departments, this study was carried out to investigate the risk factors contributing to the incidence and mortality of acute childhood poisoning.

METHODS: This hospital-based case-control study included 243 cases and 489 controls, drawn from daily admissions to the emergency departments of the included hospitals according to the inclusion and exclusion criteria.

RESULTS: Gastrointestinal poisoning was the most common poisoning type, found in $87.7 \%$ of subjects, and medications were the most common cause of poisoning (49.8\%). Multiple logistic regression analysis showed that a history of poisoning (odds ratio [OR], 10.44; 95\% confidence interval [CI], 5.58 to 19.51; $\mathrm{p}<0.001)$ and the availability of poisonous substances $(\mathrm{OR}, 8.88$; 95\% $\mathrm{CI}, 5.41$ to $14.56 ; \mathrm{p}<0.001)$ were among the most important predictors of childhood poisoning. Respiratory poisoning (OR, 6.72; $95 \% \mathrm{CI}, 1.40$ to $32.07 ; \mathrm{p}<0.05)$ and the presence of addiction in the family (OR, 4.54; $95 \% \mathrm{CI}, 1.10$ to 18.68 ; $\mathrm{p}<0.05)$ were the most important predictors of mortality among children with poisoning.

CONCLUSIONS: Addiction and the presence of physical or psychological disorders in family members, a history of poisoning, and the availability of poisonous substances were significantly associated with the incidence of childhood poisoning and resultant mortality.

KEY WORDS: Poisoning, Child, Mortality, Emergency department, Iran

\section{Correspondence: Najme Doolabi}

Department of Emergency Medicine, Faculty of Medicine, Mashhad University of Medical Sciences, Mashhad 9137913316, Iran

E-mail: drnajdoolabi@gmail.com

Received: Feb 7, 2019 / Accepted: Apr 23, 2019 / Published: Apr 23, 2019

This article is available from: http://e-epih.org/

(C) This is an open-access article distributed under the terms of the Creative Commons Attribution License (http://creativecommons.org/licenses/by/4.0/), which permits unrestricted use, distribution, and reproduction in any medium, provided the original work is properly cited.

(C) 2019, Korean Society of Epidemiology

\section{INTRODUCTION}

Poisoning is a major public health problem and a significant cause of mortality and morbidity in children, accounting for approximately $3.0 \%$ of all patients admitted to emergency departments (EDs) [1-3]. Every year, approximately 45,000 children and adolescents under the age of 20 die from poisoning, and it has been reported that the death rate from poisoning in people under the age of 20 is 1.8 per 100,000 worldwide [4,5].

Studies have suggested that the mortality rate from poisoning varies according to the cultural and geographical characteristics of different communities [6-8]. In developed countries, the mortality rate is roughly 0.5 per 100,000 people, while it is dramatically higher 
in low-income and underdeveloped countries, reaching about 2.0 per 100,000 people (almost 4 times higher than the rate in high-income and developed countries) $[9,10]$. Approximately $80 \%$ of all poisoning cases occur between the ages of 1 year and 5 years, and the most common cause of poisoning in children younger than 1 year old is medication administered by parents to children $[6,11,12]$.

The main causes of poisoning in children include the use of various drugs, exposure to hydrocarbons such as petroleum products, bleaching agents, detergents and disinfectants, plant pesticides, insecticides, and the use of cosmetics, alcohol, and narcotics; however, more than $75 \%$ of poisoning cases occur as a result of consuming poisonous substances $[13,14]$. It is also well established that increased access to and use of chemicals for various purposes such as medicine, agriculture, and industry, accompanied by changes in individuals' lifestyle, social behaviors, and economic factors, have led to increases in the rate of poisoning and mortality due to poisoning throughout the world $[13,15,16]$.

Cases of poisoning not only cause major damage to communities' health and economic well-being, but also place a tremendous psychological and emotional burden on families, which must be taken into consideration when assessing the scale of this problem $[5,8]$. Identifying the risk factors for poisoning is an essential measure for poisoning prevention programs in any society, and the rate of poisoning and resultant mortality can be reduced by modifying community-level risk factors [10].

In this regard, given the impact of factors related to acute childhood poisoning and the lack of sufficient evidence on the epidemiology of these factors in Iran, the present study aimed to identify risk factors for acute childhood poisoning, focusing both on incidence and mortality.

\section{MATERIALS AND METHODS}

This hospital-based case-control study was carried out after obtaining permission from the organizational Ethics Committee of Mashhad University of Medical Sciences. This study included patients admitted to the EDs of 2 large hospitals (Imam Reza and Ghaem) in Mashhad, Iran in 2018. All children under the age of 15 years admitted to the ED on a daily basis were included in the study based on the inclusion and exclusion criteria and after informed consent was obtained from their parents. The exclusion criteria were unwillingness of the parents to participate, childhood cognitive impairment and congenital genetic diseases, neurological and metabolic diseases, brain infections and trauma of the central and peripheral nervous systems, and physical-motor disabilities. Patients with some degree of respiratory or gastrointestinal poisoning were selected through the census sampling method and enrolled in the study based on the daily admissions records of the EDs of the abovementioned hospitals. The control group comprised children admitted to the emergency and related departments (e.g., the orthopedic department, the internal medicine department, and the burn ward) for reasons other than poisoning, who were randomly selected from the hospital records and en- rolled in the study. The individuals in both the case and control groups were selected daily, separately, and under the supervision of an emergency medicine specialist. The intended control-tocase ratio was 2:1 ( 2 controls per 1 case). After admission, the patients were transferred from the ED to the appropriate wards for hospitalization and further treatment.

Table 1. Demographic and background information of the subjects in the case and control groups

\begin{tabular}{|c|c|c|}
\hline Variables & Case & Control \\
\hline \multicolumn{3}{|l|}{ Sex } \\
\hline Male & $113(46.5)$ & $246(50.3)$ \\
\hline Female & $130(53.5)$ & $243(49.7)$ \\
\hline \multicolumn{3}{|l|}{ Age (yr) } \\
\hline$<1$ & $39(16.0)$ & $18(3.7)$ \\
\hline $1-4$ & $108(44.4)$ & $183(37.4)$ \\
\hline $4-8$ & $58(23.9)$ & $146(29.9)$ \\
\hline$>8$ & $38(15.6)$ & $142(29.0)$ \\
\hline \multicolumn{3}{|l|}{ Residence } \\
\hline Urban & $168(69.1)$ & $421(86.1)$ \\
\hline Rural & 75 (30.9) & $68(13.9)$ \\
\hline \multicolumn{3}{|l|}{ Type of poisoning } \\
\hline Gastrointestinal & $213(87.7)$ & - \\
\hline Respiratory & $30(12.3)$ & - \\
\hline \multicolumn{3}{|l|}{ History of poisoning } \\
\hline Yes & $91(37.5)$ & $24(4.9)$ \\
\hline No & $152(62.5)$ & $465(95.1)$ \\
\hline \multicolumn{3}{|l|}{ History of poisoning in family } \\
\hline Yes & $66(27.4)$ & $132(27.2)$ \\
\hline No & $175(72.6)$ & $353(72.8)$ \\
\hline \multicolumn{3}{|l|}{ Addiction in family } \\
\hline Yes & $76(31.3)$ & $93(19.0)$ \\
\hline No & $167(68.7)$ & $396(81.0)$ \\
\hline \multicolumn{3}{|c|}{$\begin{array}{l}\text { Presence of physical disease or psychologi- } \\
\text { cal disorder in family }\end{array}$} \\
\hline Yes & 48 (19.7) & $44(9.0)$ \\
\hline No & $195(80.2)$ & 445 (91.0) \\
\hline \multicolumn{3}{|l|}{ Hyperactivity } \\
\hline Yes & $75(30.4)$ & $58(11.9)$ \\
\hline No & $169(69.5)$ & $431(88.1)$ \\
\hline \multicolumn{3}{|l|}{ Father's smoking status } \\
\hline Smoker & $91(37.4)$ & $102(20.9)$ \\
\hline Non-smoker & $152(62.5)$ & $387(79.1)$ \\
\hline \multicolumn{3}{|l|}{ Mother's smoking status } \\
\hline Smoker & $50(20.6)$ & $35(7.2)$ \\
\hline Non-smoker & $193(7.2)$ & $454(92.8)$ \\
\hline \multicolumn{3}{|l|}{ Mother's occupation } \\
\hline Housewife & $134(44.8)$ & $379(77.5)$ \\
\hline Employee & $109(55.1)$ & $110(22.5)$ \\
\hline \multicolumn{3}{|l|}{ Access to poisonous substances } \\
\hline Yes & $106(65.8)$ & $46(9.4)$ \\
\hline No & $137(34.2)$ & $443(90.6)$ \\
\hline \multicolumn{3}{|l|}{ Outcome of admission } \\
\hline Discharge or improvement & $229(96.2)$ & $478(98.0)$ \\
\hline Death & $9(3.8)$ & $10(2.0)$ \\
\hline Duration of hospitalization (hr) & 29.13 & 30.86 \\
\hline
\end{tabular}

Values are presented as number (\%). 
To investigate the risk factors for childhood poisoning, checklists were used that included demographic, behavioral, and socioeconomic factors possibly affecting the risk of childhood poisoning, including the mother's employment, parental education, parental smoking, previous history of poisoning, addiction in the family, income, the presence of physical or mental illness in the family, and family size. The duration of hospitalization, the type of poisoning, and eventual clinical outcomes were also examined.

\section{Statistical methods}

Descriptive statistics, such as the mean and standard deviation, were used to present the data. The odds ratios (ORs) and 95\% confidence intervals (CIs) of the risk factors associated with the incidence of childhood poisoning were calculated using a univariate logistic regression model. In order to eliminate the effect of confounding factors, variables with a significance level of p-value $<0.1$ in the univariate logistic regression model were introduced into a multivariate logistic regression model $[17,18]$. Re- ceiver operating characteristic (ROC) analysis and the area under the ROC curve were used to assess the discriminative ability of the multiple logistic regression model. The statistical analysis was carried out using Stata version 12 (StataCorp., College Station, TX, USA), and the significance level in this study was p-value $<0.05$.

\section{RESULTS}

In this study, 243 patients comprised the case group and 489 comprised the control group. In the case group, 108 patients (44.4\%) were aged 1-4 years, and $16.0 \%$ of the children with poisoning were younger than 1 year old (Table 1). Most of the poisoned children $(87.7 \%)$ had gastrointestinal poisoning, and the remaining $12.3 \%$ of poisoning cases had respiratory poisoning. The main causes of poisoning were medications $(49.8 \%)$, detergents and disinfectants $(16.5 \%)$, carbon monoxide $(12.3 \%)$, chemicals and petroleum (12.3\%) and others (9.0\%), including drugs, alcohol,

Table 2. Risk factors for childhood poisoning by regression analysis

\begin{tabular}{|c|c|c|c|c|c|}
\hline \multirow{2}{*}{ Variables } & & \multicolumn{2}{|c|}{ Univariate } & \multicolumn{2}{|c|}{ Multiple } \\
\hline & & OR $(95 \% \mathrm{Cl})$ & p-value & OR $(95 \% \mathrm{Cl})$ & p-value \\
\hline \multirow[t]{2}{*}{ Sex } & Male & 1.00 (reference) & - & - & - \\
\hline & Female & $0.86(0.63,1.16)$ & 0.332 & - & - \\
\hline \multirow[t]{4}{*}{ Age $(y r)$} & $<1$ & $8.09(4.17,15.71)$ & $<0.001$ & $6.62(2.95,15.00)$ & $<0.001$ \\
\hline & $1-4$ & $2.20(1.43,3.38)$ & $<0.001$ & $2.79(1.62,4.80)$ & 0.010 \\
\hline & $4-8$ & $1.48(0.92,2.37)$ & 0.100 & $0.82(0.44,1.51)$ & 0.530 \\
\hline & $>8$ & 1.00 (reference) & - & 1.00 (reference) & - \\
\hline \multirow[t]{2}{*}{ Residence } & Urban & $0.36(0.25,0.52)$ & 0.001 & - & - \\
\hline & Rural & 1.00 (reference) & - & - & - \\
\hline \multirow[t]{2}{*}{ Mother's occupation } & Housewife & 1.00 (reference) & - & 1.00 (reference) & - \\
\hline & Employee & $2.80(2.01,3.89)$ & $<0.001$ & $2.96(1.92,4.55)$ & 0.010 \\
\hline \multirow[t]{2}{*}{ Mother's smoking status } & Non-smoker & 1.00 (reference) & - & 1.00 (reference) & - \\
\hline & Smoker & $3.36(2.11,5.34)$ & 0.010 & $3.44(1.79,6.59)$ & 0.010 \\
\hline \multirow[t]{2}{*}{ History of poisoning } & No & 1.00 (reference) & - & 1.00 (reference) & \\
\hline & Yes & $11.59(7.13,18.85)$ & 0.001 & $10.44(5.58,19.51)$ & $<0.001$ \\
\hline \multirow[t]{2}{*}{ Addiction in family } & No & $1.93(1.36,2.75)$ & 0.010 & $1.56(1.06,2.31)$ & 0.010 \\
\hline & Yes & 1.00 (reference) & - & 1.00 (reference) & - \\
\hline \multirow[t]{2}{*}{ History of poisoning in family } & No & $1.01(0.71,1.42)$ & 0.962 & - & - \\
\hline & Yes & 1.00 (reference) & - & - & - \\
\hline \multirow[t]{2}{*}{ Hyperactivity } & No & 1.00 (reference) & - & 1.00 (reference) & - \\
\hline & Yes & $3.25(2.20,4.79)$ & $<0.001$ & $3.24(1.93,5.42)$ & 0.010 \\
\hline \multirow[t]{2}{*}{ Father's smoking status } & Smoker & $2.71(1.60,3.18)$ & 0.001 & - & \\
\hline & Non-smoker & 1.00 (reference) & - & - & \\
\hline \multirow[t]{2}{*}{ Access to poisonous substances } & Yes & $7.45(5.01,11.06)$ & 0.001 & $8.88(5.41,14.56)$ & $<0.001$ \\
\hline & No & 1.00 (reference) & - & 1.00 (reference) & - \\
\hline \multirow{2}{*}{$\begin{array}{l}\text { Presence of physical disease or } \\
\text { psychological disorder in family }\end{array}$} & Yes & $2.48(1.59,3.87)$ & 0.010 & $2.07(1.12,3.81)$ & 0.050 \\
\hline & No & 1.00 (reference) & - & 1.00 (reference) & - \\
\hline \multirow[t]{3}{*}{ Outcome of admission } & Discharge or improvement & $0.53(0.21,1.33)$ & 0.176 & - & - \\
\hline & Death & 1.00 (reference) & - & - & - \\
\hline & Duration of hospitalization (hr) & $0.10(0.99,1.03)$ & 0.436 & - & - \\
\hline
\end{tabular}

$\mathrm{OR}$, odds ratio; $\mathrm{Cl}$, confidence interval. 
Table 3. Risk factors for mortality due to childhood poisoning by multiple logistic regression analysis

\begin{tabular}{lcccc}
\hline Variables & Death & Survival & OR (95\% Cl) & $\mathrm{p}$-value \\
\hline Mother's occupation (employee) & $5(26.3)$ & $212(30.0)$ & $0.97(0.25,3.73)$ & 0.975 \\
Mother's smoking status & $2(10.5)$ & $83(11.7)$ & $1.07(0.21,5.35)$ & 0.927 \\
History of poisoning & $3(15.8)$ & $112(15.8)$ & $0.80(0.19,3.28)$ & 0.758 \\
Presence of physical disease or psychological disorder in family & $8(42.1)$ & $531(75.1)$ & $3.36(0.86,13.04)$ & 0.070 \\
Hyperactivity & $1(5.3)$ & $131(18.5)$ & $0.26(0.03,2.17)$ & 0.217 \\
Addiction in family & $11(57.9)$ & $158(22.3)$ & $4.54(1.10,18.68)$ & 0.030 \\
Access to poisonous substances & $11(57.9)$ & $565(79.9)$ & $2.67(0.65,10.95)$ & 0.172 \\
Respiratory poisoning & $2(22.2)$ & $20(8.7)$ & $6.72(1.40,32.07)$ & 0.017 \\
\hline
\end{tabular}

Values are presented as number (\%).

$\mathrm{OR}$, odds ratio; $\mathrm{Cl}$, confidence interval.

and food. Furthermore, $37.5 \%$ of the cases $(n=91)$ had a history of poisoning, $30.4 \%$ of the cases $(n=75)$ had hyperactivity, and $31.3 \%$ of the families with poisoned children had at least 1 addicted member. Finally, $96.2 \%$ of the patients in the case group were treated or discharged, and the specific mortality rate from poisoning was $3.8 \%$. Other information about the individuals studied is shown in Table 1.

The univariate logistic regression model (Table 2) of risk factors for childhood poisoning showed that the age groups of 1-4 years old (OR, 2.20; 95\% CI, 1.43 to 3.38; $<<0.001)$ and $<1$ year old (OR, 8.09; 95\% CI, 4.17 to $15.71 ; \mathrm{p}<0.001$ ) were at the highest risk of poisoning. The mother's occupation also affected the incidence of childhood poisoning, with the children of employed mothers having a higher risk of poisoning (OR, 2.80; 95\% CI, 2.01 to $3.89 ; \mathrm{p}<0.001$ ). Children's hyperactivity was a significant independent factor that increased the risk of childhood poisoning (OR, 3.25; 95\% CI, 2.20 to 4.79; $\mathrm{p}<0.001$ ). Other factors significantly associated with an increased risk of poisoning in children $(\mathrm{p}<0.01)$ included a previous history of poisoning, addiction in the family, accessibility of poisonous substances, urban residence, and the presence of physical diseases or psychological disorders in family members.

The multiple logistic regression analysis (Table 2) showed that the following risk factors had a significant relationship with the incidence of childhood poisoning $(\mathrm{p}<0.05)$ : age, mother's occupation, mother's smoking status, history of poisoning, family history of addiction, child hyperactivity, accessibility of poisonous substances, and the presence of physical diseases or psychological disorders in family members. A history of poisoning (OR, 10.44; 95\% CI, 5.58 to 19.51; $\mathrm{p}<0.001)$, accessibility of poisonous substances (OR, 8.88; 95\% CI, 5.41 to 14.56; $<<0.001$ ), and being $<1$ year old (OR, 6.62; 95\% CI, 2.95 to 15.00; $\mathrm{p}<0.001$ ) were the most important factors influencing the incidence of childhood poisoning.

In the assessment of the model, the area under the ROC curve was 0.856 , which clearly indicated the viability of the multiple logistic regression model in this study (Figure 1).

As shown in Table 3, respiratory poisoning (OR, 6.72; 95\% CI, 1.40 to $32.07 ; \mathrm{p}<0.05)$ and a family history of addiction (OR, 4.54; $95 \% \mathrm{CI}, 1.10$ to 18.68 ; $\mathrm{p}<0.05)$ increased the risk of mortality in

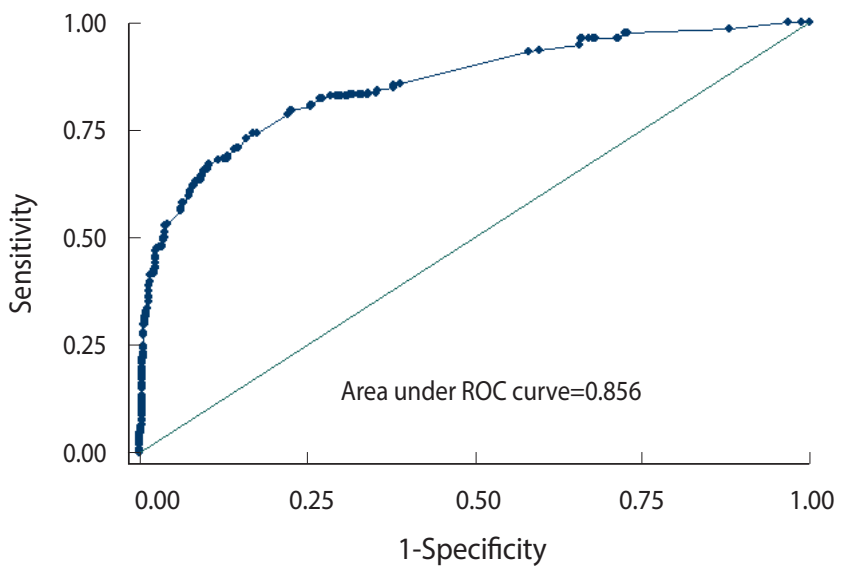

Figure 1. Evaluation of the multiple logistic regression model through the area under the receiver operating characteristic (ROC) curve.

poisoned children. Other factors, such as mother's occupation, mother's smoking status, hyperactivity, accessibility of poisonous substances, a previous history of poisoning, and the presence of physical diseases or psychological disorders in family members did not have a significant relationship with mortality in poisoned children.

\section{DISCUSSION}

Poisoning is one of the most important preventable factors contributing to the hospitalization and death of children in EDs. The results of this study, which aimed to investigate the risk factors affecting childhood poisoning, clearly identified factors associated with the incidence and mortality of poisoning in children. Although the epidemiology of childhood poisoning shows significant geographic variation, regions with similar socioeconomic and cultural factors tend to have similar epidemiological patterns [19]. Age is one of the most important factors affecting the incidence of childhood poisoning, but the role of age varies across regions. In developing countries, the highest incidence of poisoning is in children aged $<5$ years, and such cases are often involuntary and out of curiosity, while in developed countries, the highest in- 
cidence of poisoning is observed in individuals over the age of 60 [19-21]. Talebian et al. [22] and Andiran \& Sarikayalar [23] showed that the age group of 1-5 years had the highest frequency of poisoning. In our study, children under the age of 4 years had the highest incidence and risk of poisoning, which is consistent with the results of other studies. Lamireau et al. [24] also showed that more than $80 \%$ of childhood poisoning cases occurred in children younger than 6, while Pawłowicz et al. [3] found the age group of 16-18 to have the highest rate of poisoning. They reported that poisoning in children younger than 5 years was observed in fewer than $15 \%$ of the subjects, which is inconsistent with our study results and shows the epidemiological differences in poisoning depending on countries' cultural and social development.

In this study, maternal factors such as smoking and occupational status were associated with the risk of poisoning in children. Studies in developed countries have concluded that the absence of at least 1 parent could increase the risk of unintentional poisoning in children [12]. Mansori et al. [18] likewise showed that maternal factors such as employment, education, and smoking status increased the risk of childhood poisoning, which is consistent with the results of our study; in this study, the risk of poisoning in children with smoking mothers was 3.36 times higher than in those with non-smoking mothers. Maternal employment also increased the risk of childhood poisoning by 2.8 times.

Children's hyperactivity has also been identified as an important factor in the prevalence of poisoning, and even injuries and traumas, in this age group. Ruiz-Goikoetxea et al. [25] showed a clear relationship between children's hyperactivity and poisoning. The results of this study indicated that hyperactive children were at a high risk of poisoning, which is in line with the results of previous studies. Brayden et al. [26] suggested that factors such as easy access to poisonous substances and children's curiosity were among the most important risk factors for poisoning. Even the absence of 1 parent during the day due to their occupation, especially mothers, was associated with an increased risk of poisoning in children [12,27]. Accessibility of poisonous substances, addiction in the family, the presence of a physical or psychological illness in the family, and a history of poisoning were among the other factors that increased the risk of childhood poisoning $[10,17,18]$. The results of studies by Mansori et al. [18] and Dayasiri et al. [28] showed that inaccessibility of substances that might cause poisoning played a protective role against childhood poisoning. In contrast, easy access of children to poisonous substances was considered to be one of the most important factors affecting childhood poisoning. The presence of addiction among family members could increase the risk of childhood poisoning $[10,18]$. However, Dayasiri et al. [28] reported that drug and alcohol addiction significantly reduced the risk of childhood poisoning, which is not consistent with the results of our study. In addition, the results of studies that are consistent with ours confirmed that parents' level of knowledge and their attitude towards poisonous substances were among the most important risk factors $[10,18,29]$, as observed in the present study.
Addiction in the family and respiratory poisoning were associated with mortality in poisoned children in this study. Respiratory poisoning, mainly due to carbon monoxide, increased the risk of child mortality by 6.7 times compared to gastrointestinal poisoning. This underscores the important role of respiratory poisoning caused by carbon monoxide in child mortality in developing countries. Carbon monoxide poisoning has symptoms ranging from mild (e.g., headache, faint, lethargy, and myalgia) to severe (e.g., diplopia, syncope, coma, cardiac arrest, and death) [30-32]. Perhaps due to the co-occurrence of other risk factors and access to poisonous substances, addiction in family members increased the mortality risk of poisoned children, which should be taken into account $[17,18]$.

Although recall bias is a limitation of case-control studies, its likelihood was low in the present study due to the use of various information sources (interviews with family members of the poisoned children). Furthermore, the generalizability of the results of hospital-based case-control studies can be a challenge, although this limitation was minimized by selecting 2 major large hospitals (Imam Reza and Ghaem Hospitals) that accounted for roughly $90 \%$ of all poisoning cases in the region.

The results of this study showed a clear relationship between the incidence of childhood poisoning and factors such as addiction and the presence of physical or mental illnesses in family members, a history of poisoning, access of children to poisonous substances, the mother's smoking and employment status, and hyperactivity of the children. Furthermore, respiratory poisoning and addiction in family members were associated with an increased risk of mortality among poisoned children in this study. In general, the incidence and mortality rate of childhood poisoning could be reduced by the implementation of educational programs and interventions.

\section{CONFLICT OF INTEREST}

The authors have no conflicts of interest to declare for this study.

\section{ACKNOWLEDGEMENTS}

The authors are grateful to all the personnel of Imam Reza Hospital and Ghaem Hospital as well as the Vice-Chancellor for Research, Mashhad University of Medical Sciences, for their contribution to the implementation of this research projects.

\section{ORCID}

Hamideh Feiz Disfani: http://orcid.org/0000-0003-4554-9008; Mostafa Kamandi: https://orcid.org/0000-0001-8518-0108; Seyed Mohammad Mousavi: http://orcid.org/0000-0003-3032-5335; Sayyed Majid Sadrzadeh: http://orcid.org/0000-0002-7261-025X; Roohie Farzaneh: https://orcid.org/0000-0002-9723-2451; Najme Doolabi: http://orcid.org/0000-0002-9400-4410; Kazem Rahmani: http://orcid.org/0000-0002-6940-7947 


\section{REFERENCES}

1. Bronstein AC, Spyker DA, Cantilena LR Jr, Green JL, Rumack BH, Heard SE, et al. 2007 Annual report of the American Association of Poison Control Centers' National Poison Data System (NPDS): 25th annual report. Clin Toxicol (Phila) 2008;46:927-1057.

2. Kissoon N, Argent A, Devictor D, Madden MA, Singhi S, van der Voort E, et al. World Federation of Pediatric Intensive and Critical Care Societies-Its global agenda. Pediatr Crit Care Med 2009; 10:597-600.

3. Pawłowicz U, Wasilewska A, Olański W, Stefanowicz M. Epidemiological study of acute poisoning in children: a 5-year retrospective study in the Paediatric University Hospital in Bialystok, Poland. Emerg Med J 2013;30:712-716.

4. Antonogeorgos G, Panagiotakos DB, Priftis KN, Tzonou A. Logistic regression and linear discriminant analyses in evaluating factors associated with asthma prevalence among 10-to 12-yearsold children: divergence and similarity of the two statistical methods. Int J Pediatr 2009;2009:952042.

5. Oguche S, Bukbuk DN, Watila IM. Pattern of hospital admissions of children with poisoning in the Sudano-Sahelian North eastern Nigeria. Niger J Clin Pract 2007;10:111-115.

6. Agarwal G, Bithu K, Agarwal R. An epidemiological study of acute poisoning in children in a tertiary care hospital of western Rajasthan, India. Int J Contemp Pediatrics 2016;3:1249-1251.

7. Raman R, Kumar S, Muthukrishnan L. A hospital-based epidemiologic study on acute pediatric poisonings in Chennai, India. Asia Pac J Med Toxicol 2015;4:156-160.

8. Centers for Disease Control (CDC). Cost of injury--United States: a report to Congress, 1989. MMWR Morb Mortal Wkly Rep 1989; 38:743-746.

9. Alazab RM, Elmougy MT, Fayad RA, Abdelsalam HF, Mohamed AS. Risk factors of acute poisoning among children: a study at a poisoning unit of a university hospital in Egypt. South East Asia J Public Health 2002;2:41-47.

10. Soori H. Developmental risk factors for unintentional childhood poisoning. Saudi Med J 2001;22:227-230.

11. Mutlu M, Cansu A, Karakas T, Kalyoncu M, Erduran E. Pattern of pediatric poisoning in the east Karadeniz region between 2002 and 2006: increased suicide poisoning. Hum Exp Toxicol 2010;29: 131-136.

12. Petridou E, Kouri N, Polychronopoulou A, Siafas K, Stoikidou M, Trichopoulos D. Risk factors for childhood poisoning: a case-control study in Greece. Inj Prev 1996;2:208-211.

13. Fan AY, Che AH, Pan B, Yang C, Coulter CV, Shieffelbien L, et al. Investigating childhood and adolescence poisoning exposures in New Zealand reported to the national poisons centre during 20002009. Asia Pac J Med Toxicol 2013;2:52-57.

14. Kliegman RM, Behrman RE, Jenson HB, Stanton BM. Nelson textbook of pediatrics. 18th ed. Amsterdam: Elsevier Health Sciences; 2007, p. 707-713.

15. Krenzelok EP, Mrvos R. Toxic Christmas and New Year holiday plants... or are they? Asia Pac J Med Toxicol 2015;4:64-67.

16. Youniss J, Litovitz T, Villanueva P. Characterization of US poison centers: a 1998 survey conducted by the American Association of Poison Control Centers. Vet Hum Toxicol 2000;42:43-53.

17. Khosravi Shadmani F, Rajabi A, Gholami A. Compare the estimated odds ratios from logistic regression and conditional logistic regression in the case-control study determination risk factors for unintentional childhood poisoning of children in Tehran. Zanko J Med Sci 2016;6:10-21 (Persian).

18. Mansori K, Soori H, Farnaghi F, Khodakarim S, Mansouri Hanis S, Khodadost M. A case-control study on risk factors for unintentional childhood poisoning in Tehran. Med J Islam Repub Iran 2016;30:355.

19. Hassan BA, Siam MG. Patterns of acute poisoning in childhood in Zagazig, Egypt: an epidemiological study. Int Sch Res Notices 2014;2014:245279.

20. Ozdogan H, Davutoglu M, Bosnak M, Tutanc M, Haspolat K. Pediatric poisonings in southeast of Turkey: epidemiological and clinical aspects. Hum Exp Toxicol 2008;27:45-48.

21. Schmertmann M, Williamson A, Black D, Wilson L. Risk factors for unintentional poisoning in children aged 1-3 years in NSW Australia: a case-control study. BMC Pediatr 2013;13:88.

22. Talebian A, Doroodgar A, Salehi I, Akbari H. Epidemiologic study of poisoning in children admitted at Shaheed Beheshti Hospital of Kashan during 1997-2001. Feyz 2006;10:46-49 (Persian).

23. Andiran N, Sarikayalar F. Pattern of acute poisonings in childhood in Ankara: what has changed in twenty years? Turk J Pediatr 2004;46:147-152.

24. Lamireau T, Llanas B, Kennedy A, Fayon M, Penouil F, FavarellGarrigues JC, et al. Epidemiology of poisoning in children: a 7-year survey in a paediatric emergency care unit. Eur J Emerg Med 2002;9:9-14.

25. Ruiz-Goikoetxea M, Cortese S, Magallón S, Aznárez-Sanado M, Álvarez Zallo N, Luis EO, et al. Risk of poisoning in children and adolescents with ADHD: a systematic review and meta-analysis. Sci Rep 2018;8:7584.

26. Brayden RM, MacLean WE Jr, Bonfiglio JF, Altemeier W. Behavioral antecedents of pediatric poisonings. Clin Pediatr (Phila) 1993; 32:30-35.

27. Baaker RH. Risk factors for childhood poisoning: a case-control study in Baghdad. Mustansiriya Med J 2010;9:6-12.

28. Dayasiri MB, Jayamanne SF, Jayasinghe CY. Risk factors for acute unintentional poisoning among children aged 1-5 years in the rural community of Sri Lanka. Int J Pediatr 2017;2017:4375987.

29. Ramos CL, Barros HM, Stein AT, Costa JS. Risk factors contributing to childhood poisoning. J Pediatr (Rio J) 2010;86:435-440.

30. Hancı V, Ayoğlu H, Yurtlu S, Yildırım N, Okyay D, Erdoğan G, et al. Effects of acute carbon monoxide poisoning on the P-wave and QT interval dispersions. Anadolu Kardiyol Derg 2011;11:48-52.

31. Sircar K, Clower J, Shin MK, Bailey C, King M, Yip F. Carbon monoxide poisoning deaths in the United States, 1999 to 2012. Am J Emerg Med 2015;33:1140-1145.

32. Unsal Sac R, Taşar MA, Bostancı İ, Şimşek Y, Bilge Dallar Y. Characteristics of children with acute carbon monoxide poisoning in Ankara: a single centre experience. J Korean Med Sci 2015;30:18361840. 